\title{
Commentary: With surgical revascularization, sometimes less is more
}

\author{
Sudarshan Balla, MD, ${ }^{\mathrm{a}}$ Vinay Badhwar, MD, ${ }^{\mathrm{b}}$ and Harold G. Roberts, Jr, MD
}

\footnotetext{
From the ${ }^{\mathrm{a} D i v i s i o n}$ of Cardiology, West Virginia University, and ${ }^{\mathrm{b}}$ Department of Cardiovascular and Thoracic Surgery, West Virginia University, WVU Heart and Vascular Institute, Morgantown, WVa.

Disclosures: Authors have nothing to disclose with regard to commercial support.

Received for publication Aug 1, 2019; accepted for publication Aug 1, 2019; available ahead of print Oct 25, 2019.

Address for reprints: Harold G. Roberts, Jr, MD, Department of Cardiovascular and Thoracic Surgery, West Virginia University, 1 Medical Center Dr, Morgantown, WV 26506 (E-mail: Harold.roberts@wvumedicine.org). J Thorac Cardiovasc Surg 2020;159:1807-8 $0022-5223 / \$ 36.00$

Copyright (C) 2019 Published by Elsevier Inc. on behalf of The American Association for Thoracic Surgery https://doi.org/10.1016/j.jtcvs.2019.08.021
}

The role of cardiac magnetic resonance imaging in the assessment of myocardial viability comes from the seminal study by Kim and colleagues ${ }^{1}$ that showed transmurality of infarct assessed by late gadolinium enhancement (LGE) is inversely related to functional recovery after revascularization. In the current issue of the Journal, Hwang and colleagues $^{2}$ sought to assess the serial changes in segmental myocardial function after coronary artery bypass grafting in patients with significant left ventricular dysfunction using cardiac magnetic resonance imaging preoperatively, 3 months, and 1 year after surgery. The majority of the dysfunctional segments $(56.5 \%)$ showed improvement in contractility at 3 months, with a $5 \%$ incremental improvement in functional recovery at 1 year. The authors also reported improvement in systolic function in $30 \%$ of the segments with infarct thickness greater than $50 \%$ of the left ventricular wall (Figure 1).

Several differences exist between the current study by Hwang and colleagues and previous studies using LGE cardiac magnetic resonance imaging to assess viability. ${ }^{1,3}$ The use of left internal mammary artery and complete revascularization was achieved in majority of patients and most important of all, only segments with patent grafts were included in the analysis. Hwang and colleagues ${ }^{2}$ reported nearly $40 \%$ of segments with $51 \%$ to $75 \%$ infarct thickness improved at 3 months postrevascularization. This is in contrast to the study by Kim and colleagues, ${ }^{1}$ who reported only $10 \%$ of the segments with $51 \%$ to $75 \%$ infarct thickness showed any improvement in contractile function at 3 months. What could be the potential explanation for these findings?

The current study has a greater number of patients with acute coronary syndrome $(67 \%)$ or recent myocardial infarction $(25 \%)$. The presence of myocardial edema surrounding an infarct also shows LGE and hence may overestimate the transmurality of the infarct. This could also explain why acute coronary syndrome is a predictor

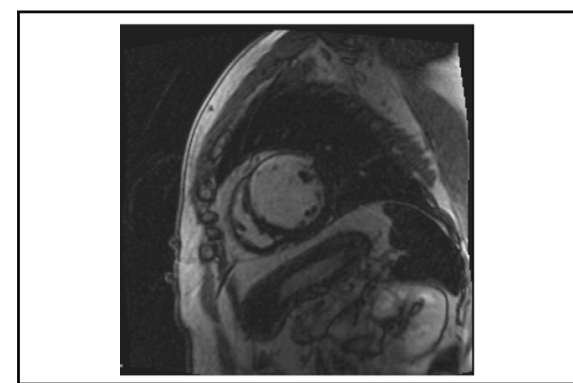

Delayed gadolinium enhancement cardiac MR image of short axis of left ventricle.

\section{Central Message}

Late gadolinium enhancement by cardiac MRI in patients with left ventricular systolic dysfunction and coronary artery disease predicts functional recovery after revascularization. The current study shows that the success of surgical revascularization with regards to functional recovery is dependent on the use of left internal mammary artery, graft patency, optimal medical therapy and complete revascularization if feasible. However, one should not risk early graft closure by pursuing poor target vessels.

See Article page 1798.

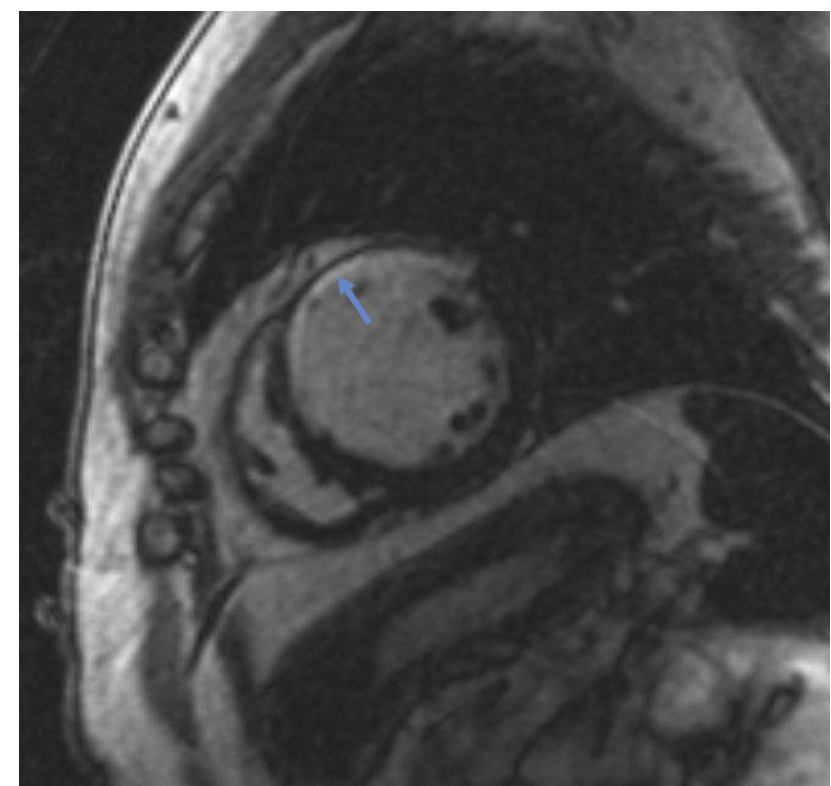

FIGURE 1. Delayed gadolinium enhancement image (phase-sensitive) of short axis at the mid-ventricle level showing a $50 \%$ transmural thickness of subendocardial infarct in the anteroseptum and anterior wall (arrow). 
of recovery of segmental function. There is a statistically nonsignificant improvement even in segments with occluded grafts. This could be secondary to the improved collateral flow as well as treating ischemia with optimal medical therapy.

We respectfully disagree with the authors' perspective statement that "myocardial revascularization should be performed completely." In their zeal to achieve the mantra of complete revascularization, virtually all experienced adult cardiac surgeons have seen the lack of benefit by grafting small-caliber, diseased target vessels with limited runoff. Indeed, in these situations, sometimes less is more.

In summary, viability cannot be viewed as a binary variable. Despite the limitations of the current study, we can conclude that there exists a continuum in which there is a decreased probability of recovery despite the thickness of the infarct being $>50 \%$ or even $>75 \%$. The quest for the gold standard test to accurately predict functional recovery in such segments continues. However, there must be equipoise and common sense in surgical decision-making to know when the risks outweigh the benefits of revascularizing every target.

\section{References}

1. Kim RJ, Wu E, Rafael A, Chen EL, Parker MA, Simonetti O, et al. The use of contrast-enhanced magnetic resonance imaging to identify reversible myocardial dysfunction. N Engl J Med. 2000;343:1445-53.

2. Hwang HY, Yeom SY, Park E-A, Lee W, Jang M-J, Kim K-B. Serial cardiac magnetic resonance imaging after surgical coronary revascularization for left ventricular dysfunction. J Thorac Cardiovasc Surg. 2020;159:1798-805.

3. Selvanayagam JB, Kardos A, Francis JM, Wiesmann F, Petersen SE, Taggart DP, et al. Value of delayed-enhancement cardiovascular magnetic resonance imaging in predicting myocardial viability after surgical revascularization. Circulation. 2004; 110:1535-41 